\title{
Mapeamento das perdas da armazenagem da soja: um estudo de caso em uma cooperativa de armazenagem de grãos
}

\author{
Mapping the Losses of Soy Storage: a case study at a grain storage cooperative
}

\begin{abstract}
Resumo
Os problemas de infraestrutura em armazéns de soja no Brasil são fatores que atrapalham a competitividade da cadeia. Tais fatores estão diretamente relacionados às perdas dos grãos no processo de armazenagem. $\mathrm{O}$ objetivo deste trabalho foi mapear as operações relacionadas ao processo de armazenagem da soja em uma cooperativa de grãos com o intuito de identificar etapas onde há maior incidência de perdas. Este estudo, de caráter aplicado e exploratório, fez uso do estudo de caso, desenvolvido com o auxílio de entrevistas semiestruturadas com colaboradores do setor, bem como observações diretas não-participantes para o levantamento dos dados. Como principais resultados destaca-se que as perdas dos grãos podem derivar de diversas operações inerentes ao processo, notadamente na movimentação dos grãos, no transbordo nas moegas, no processo da secagem e da própria armazenagem. Constatou-se também que para mitigar essas perdas são necessários esforços substanciais, e dependem, sobremaneira, de investimentos em ativos específicos.
\end{abstract}

Palavras-chave: perdas, soja, armazenagem, mapeamento de processos.

\begin{abstract}
The problems of infrastructure in soybean warehouses in Brazil are factors that hinder the competitiveness of the chain. These factors are directly related to grain losses in the storage process. The objective of this work was to map the operations related to the soybean storage process in a grain cooperative in order to identify stages where there is a higher incidence of losses. This applied and exploratory study made use of the case study, developed with the aid of semi-structured interviews with employees of the sector, as well as direct nonparticipant observations to collect the data. The main results show that the losses of the grains can derive from several operations inherent to the process, notably grain movement, transshipment in hoppers, drying process and storage. It has also been found that to mitigate these losses substantial efforts are required, and depend heavily on investments in specific assets.
\end{abstract}

Keywords: loss, soy, storage, process mapping.

Fabrício Oliveira Leitão ${ }^{\mathrm{I}}$, Guilherme José Oppelt ${ }^{\mathrm{II}}$, Warley Henrique da Silva ${ }^{\mathrm{III}}$.

${ }^{\text {I } U n i v e r s i d a d e ~ d e ~ B r a s i ́ l i a ~(U n B), ~ B r a s i l i a, ~ D F . ~ f a b r i c i o f o l @ h o t m a i l . c o m ~}$

${ }^{\text {II }}$ Universidade de Brasília (UnB), Brasilia, DF. guillhermegjg@hotmail.com

${ }^{\text {III }}$ Faculdade CNEC Unai. Unai, MG. warleyhsunai@gmail.com 


\section{Introdução}

Sabe-se que uma vez concluídos os processos inerentes ao subsistema de suprimentos, a logística se ocupará da movimentação física dos produtos, como transporte interno, manuseio, armazenagem primária e estoques primários (subsistema de apoio à produção) e, por fim, tratará da entrega do produto ao consumidor final (subsistema de distribuição) (BALLOU, 1993).

Uma das atividades vinculadas à logística e aos subsistemas logísticos é a armazenagem. Dentro do conceito de logística integrada, a armazenagem tem um papel fundamental e estratégico, pois auxilia no controle do tempo e do volume de insumos/produtos a ser distribuído, integrando as áreas da cadeia logística com o cliente, conforme sua necessidade (BOWERSOX; CLOSS, 2006).

Por sua capacidade de proporcionar vantagem competitiva, a logística é adotada nos mais diversos setores produtivos. O agronegócio é um deles. Segundo a Companhia Nacional de Abastecimento (CONAB, 2016), esse tem sido um dos setores econômicos mais importantes para o país, sobretudo em função da contribuição significativa nos sucessivos saldos positivos da balança comercial, o que proporciona suporte à consolidação da estabilização da economia nacional.

No ano de 2019, o Brasil é um dos países que mais se destaca no cenário mundial quando se trata de agricultura, devido sua crescente expansão na produção de grãos, em especial o cultivo da soja. Este destaque se deve aos investimentos realizados em pesquisas e tecnologia na produção agrícola, ajudando a contribuir para a expansão da balança comercial.

Porém, este desempenho não está sendo acompanhado de um progresso no que diz respeito aos serviços de comercialização agrícola, principalmente as relacionadas a armazenagem e o transporte, o que tem atrapalhado a competitividade do produto brasileiro nos mercados interno e externo.

A armazenagem de grãos no Brasil não tem acompanhado ao longo dos anos o ritmo de crescimento das safras, verificando-se déficits em determinadas áreas, principalmente naquelas de incorporação recente ao processo produtivo (GABAN; SILVA; GUARNIERI; BRISOLA, 2017).

Segundo a Conab, a safra de 2015/2016 teve uma produção de cerca de 210,3 milhões de toneladas de grãos produzidos. A capacidade de armazenagem foi de 153 milhões de toneladas de grãos. Ainda há um déficit de 58,5 milhões de toneladas a serem armazenadas (CONAB, 2016). No que tange a cadeia produtiva da soja, este problema é ainda mais relevante.

A soja é o grão de maior produção nacional. Na safra de 2015/2016 foram produzidos cerca de 95 milhões de toneladas, onde o Brasil se posicionou como o segundo maior produtor do mundo, atrás apenas dos Estados Unidos. No Brasil, parte considerável da produção de soja, cerca de 52 milhões de toneladas, é destinada para o mercado externo, tendo como principal comprador a China (CONAB, 2016).

Analisando a produção de soja, Moraes, Boiko e Biasi (2009) ressaltam alguns pontos passíveis de perdas. Destacam questões associadas ao plantio, colheita, armazenagem, processamento, transporte e distribuição. Afirmam ainda que de $5 \%$ a $10 \%$ de tudo que é cultivado acabam perdido na propriedade ou durante o processo de armazenagem e transporte.

Campos e Fachel (2010) reconhecem que o Brasil é o país que consegue a maior produtividade de soja por hectare do mundo. Quando comparado aos Estados Unidos, o Brasil produz $11 \%$ mais por hectare, porém perde competitividade devido a falta de qualidade das operações de transporte e armazenagem. 
Nos últimos anos, a produção de grãos tem crescido a taxas anuais acentuadas, em razão das excelentes produtividades obtidas através do aumento da tecnologia utilizada nas lavouras e com a modernização das máquinas e implementos agrícolas (CONAB, 2016).

Por um longo período, praticamente não ocorreram investimentos no setor, e como nos últimos anos a agricultura brasileira vem apresentando expressivas taxas de crescimento em relação a outros setores da economia, este fato tem criado problemas regionais em termos de logística, especialmente em questões relacionadas ao armazenamento e transporte de grãos (MORAES; BOIKO; BIASE, 2009).

De acordo com dados da Conab, existe um total de 17.707 armazéns cadastrados no Brasil, e existe um déficit de 58,5 milhões de toneladas. O Brasil produz cerca de 208 milhões de toneladas de grãos, mas somente cerca de 155 milhões são armazenadas. Esse déficit na armazenagem se dá pela falta de investimentos e pelo alto custo para adquirir um armazém (CONAB, 2016; LEITÃO, GRANEMANN e SILVA, 2016; LEITÃO, et. al, 2018).

Com a abertura de novas fronteiras agrícolas no Brasil, principalmente em estados como Maranhão, Tocantins, Piauí e Bahia, e das já conhecidas da região Centro-Oeste, há uma demanda maior de investimentos, pois com a quantidade de grãos produzidos, aumenta a necessidade de ampliar a capacidade de armazenagem. Essas novas áreas são quase desprovidas de infraestrutura de armazenagem, e carente de condições logísticas para escoamento da produção (GABAN; SILVA; GUARNIERI; BRISOLA, 2017).

Segunda a Confederação Nacional da Agricultura - CNA (2015), a carência de unidades armazenadoras concentra-se nas regiões de fronteira agrícola. Maior celeiro do país, o Mato Grosso, com produção de 51,203 milhões de toneladas na safra 2014/2015, tem capacidade para estocar apenas 32,288 milhões. Falta espaço adequado para guardar 18,814 milhões de toneladas.

Para tentar atenuar esse déficit no armazenamento de grãos, seria interessante que cada produtor tivesse seu próprio armazém, o que traria a redução dos custos logísticos como um todo, pois só haveria a movimentação dos grãos quando houvesse necessidade, não sendo necessário enviar para algum armazém distante da fazenda do produtor. Todavia, sabe-se que os investimentos na construção de um armazém são elevados, e que o acesso à financiamento é moroso e burocrático (LEITÃO, GRANEMANN e SILVA, 2016; LEITÃO, et. al, 2018).

Corroborando com o que foi dito anteriormente, o Brasil tem enfrentado grandes problemas em decorrência da capacidade estática limitada (MAIA et al., 2013; LIMA JÚNIOR et al., 2012) e das práticas inadequadas realizadas durante o armazenamento (LIMA JÚNIOR et al., 2012).

Estima-se que no Brasil, $20 \%$ da produção anual de grãos seja perdida entre a colheita e o armazenamento (CAMPOS, 2008). Somente no armazenamento podem ocorrer perdas de cerca de $15 \%$ dos grãos, causados por diversos fatores, como: pragas, qualidade dos grãos ou pelas instalações físicas das unidades armazenadoras que muitas vezes estão em péssima qualidade (LIMA JÚNIOR et al., 2012).

Nas diversas cadeias produtivas do agronegócio a armazenagem é um processo de suma importância, pois de nada vale produzir bem, com qualidade e produtividade elevadas, se a produção ficar comprometida devido a um processo inadequado de armazenamento (BAILEY, 1974).

Diante do que foi contextualizado, o objetivo geral deste trabalho foi mapear as operações inerentes ao processo de armazenagem da soja em um armazém localizado em Unaí, MG com o intuito de identificar as etapas onde há maior incidência de perdas do grão para, posteriormente, levantar junto à literatura especializada estudos que possam ajudar a propor melhorias, no sentido de mitigar essas perdas. 


\section{Revisão teórica}

\subsection{Logística e seus subsistemas}

Segundo Bowersox e Closs (2006), a logística envolve a integração de informações, transporte, estoque, armazenamento, manuseio de materiais e embalagem. Geralmente, as mercadorias necessitam ser armazenadas em momentos específicos durante o processo logístico. Um exemplo é o caso dos grãos, que na pós-colheita, por insuficiência da rede de armazenagem ou por má conservação de estradas e inadequação do transporte utilizado, há grandes perdas, tanto qualitativas quanto quantitativas.

A logística passa a fazer parte do cenário empresarial, apresentando importância nas transações comerciais, como forma de incrementar as exportações. Segundo Ballou (1993) a logística pode servir como um fator de destaque, agregando valor ao produto ou serviço prestado como forma de redução de custos, uma vez que a empresa pode conseguir vantagem competitiva sustentável por meio de custos ou de diferenciação.

Segundo Bowersox e Closs (2006), o propósito do suprimento é dar apoio à produção ou à revenda, possibilitando comprar em tempo hábil, ao menor custo total, e se responsabilizando também pela organização da movimentação de entrada de insumos e matérias-primas dos fornecedores.

Ayers (2006) definiu a Supply Chain Management (SCM) como as atividades de planejamento, manutenção e operação dos processos na cadeia de suprimentos, incluindo aqueles responsáveis por formar as características estendidas dos produtos, a fim de satisfazer as necessidades do consumidor final.

Atualmente, a cadeia produtiva de grãos, também conhecida como rede de suprimentos ou abastecimento, não pode ser vista ou interpretada de maneira isolada, pois as consequências das ações dos atores presentes na rede afetam a competitividade de todos os envolvidos, bem como das demais cadeias produtivas dependentes dela, conforme relatado por Slack et al., (2009).

A distribuição física é a última etapa da logística, responsável por analisar o produto antes de chegar ao cliente final. É através dela que o consumidor tem acesso ao produto que atenda às suas necessidades. Segundo Bowersox e Closs (2006) a distribuição física influencia as vendas na medida em que proporciona a disponibilização dos produtos de forma econômica e em tempo hábil.

Para Novaes (2004), o objetivo do subsistema da distribuição física é o de levar os produtos certos para os lugares certos, no momento correto, com o nível de serviço desejado e pelo menor custo possível.

Para o setor agrícola existem cinco tipos de modais para transporte de cargas, cada um com suas características próprias: ferroviário, rodoviário, hidroviário, dutoviário e aeroviário. Cabe ao empresário escolher qual modal atende as suas necessidades, de maneira que seu produto chegue até o destino final sem sofrer danos a sua qualidade e também analisando a sua disponibilidade na região onde está inserido (ALVARENGA; NOVAES, 2000).

Além do transporte, outros fatores determinam a melhoria de um sistema de distribuição, como cita Novaes (2004): instalações físicas, estoque de produtos ao longo do processo, informações diversas, softwares de planejamento e controle, estrutura de custos e pessoal.

Uma infraestrutura eficiente aliada a um bom sistema de transportes torna essa distribuição mais rápida e econômica, o que possibilita custos totais menores e, consequentemente, preços finais dos produtos mais baixos, beneficiando toda a cadeia (GIOVINE; MELO, 2011). 
A infraestrutura no setor agrícola e de exportação se constitui no principal problema condicionante do crescimento do comércio brasileiro. Mesmo assim, pouco tem sido feito para solucionar os problemas enfrentados (GIOVINE; MELO 2011).

\subsection{Armazenagem de grãos}

Os armazéns estão presentes nos mais diversos elos de escoamento da soja para exportação, pois durante o processo de comercialização há a necessidade de armazenagem para a retirada de impurezas e redução de umidade para a melhor conservação do produto e aperfeiçoamento do modal de transporte utilizado (FERRARI, 2006).

Quando se analisa a questão de logística, percebe-se que a capacidade de expansão da agricultura brasileira está próxima do seu limite, pela falta de infraestrutura para escoar a produção e pela incapacidade de armazenar de forma adequada a safra (SNA, 2016).

A armazenagem tem o objetivo de proteger e dar segurança aos produtos. Além disso, pode fazer parte do processo de produção. Algumas decisões típicas relacionadas à armazenagem de produtos são: a determinação do espaço de armazenagem, o layout, projetos de docas, a configuração do armazém, a disposição dos produtos no estoque de acordo com o tipo de produto, e o tipo de cliente ou rotatividade (MORABITO; IANNONI, 2007).

A armazenagem correta dos grãos traz algumas vantagens: diminuição das perdas quantitativas e qualitativas que ocorrem no campo ocasionado pelo atraso da colheita; e economia do transporte, notadamente pelos altos preços dos fretes praticados no Brasil; quando o transporte for necessário, terá o custo diminuído por não realizar movimentação desnecessária; maior rendimento na colheita por evitar a espera dos caminhões nas filas nas unidades que fazem o armazenamento, entre outros.

Importante ressaltar que durante o armazenamento, somente as mantém. Boas práticas de armazenamento conservam a qualidade física e fisiológica dos grãos (BAUDET; VILELA, 200o).

Caso as unidades armazenadoras não observem as técnicas adequadas de armazenagem para cada tipo de grão poderá ocasionar perdas (D’ARCE, 2012). Essas podem ocorrer pelo processo inadequado de secagem dos grãos (perda de peso), limpeza e movimentação desnecessária (D’ARCE, 2012).

Segundo Instituto Brasileiro de Geografia e Estatística (IPEADATA, 2017) houve uma queda no número de armazéns cadastrados e ativos no Brasil, de 7.927 unidades no final de 2014, para 7.858 unidades em 2015.

Mesmo com a falta de espaço para manter os grãos armazenados, não há impacto relevante com a comercialização ou com perdas de grãos, devido ao fato de sua alta rotatividade de mercado.

A localização dos armazéns também deve ser levada em consideração, pois não adianta ter diversos armazéns e alta capacidade de armazenagem se estiver distante das unidades produtoras rurais, acarretando em aumento dos custos logísticos.

Segundo Araújo (2005), a armazenagem se classifica em:

- Primária - guarda os produtos ainda na fazenda, em um curto espaço de tempo.

- Local - armazéns localizados no município onde são produzidos os grãos.

- Regional - concentra a produção de vários produtos em um determinado local de uma região que facilita o depósito de grãos. 
- Terminal - armazenagem regional em terminais intermodais.

- De distribuição - processo inverso, de saída de produtos para armazéns menores.

- Final - nível de última intermediação antes do consumidor.

O armazenamento realizado dentro das próprias fazendas ajuda a mitigar as perdas, reduzir os gastos dos serviços executados e cobrados pelos armazenadores e, também, os custos com frete, além de possibilitar a geração de empregos no campo. O produtor dependente de espaço em armazéns de terceiros não realiza suas atividades de acordo com suas necessidades, podendo perder o controle e a oportunidade de melhor comercializar o seu produto.

Mesmo as vantagens sobre ter armazéns próprios, muitas produtores ainda são reticentes pelo fato de ter que fazer investimentos de alto valor, e também pelo fato de ter dificuldades em conseguir recursos para essa construção.

\subsection{Cadeia produtiva da soja e suas especificidades}

A cadeia produtiva da soja é de suma importância para a economia brasileira, e destaca-se como a principal cultura explorada no mercado interno (PINAZZA, 2006). A figura 1 mostra como está organizada a cadeia produtiva da soja no Brasil.

Figura 1: Cadeia produtiva da soja no Brasil

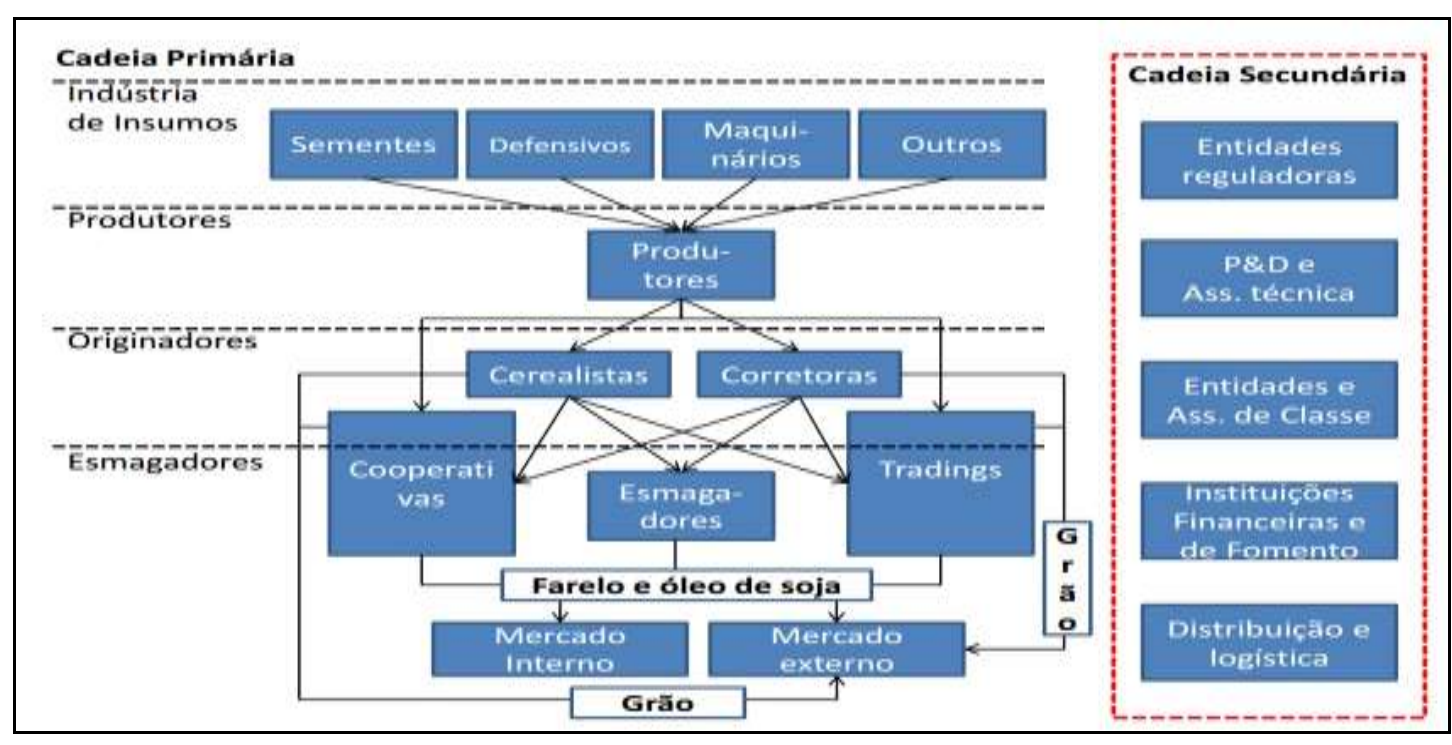

Fonte: Adaptado de Roberti, Neto e Correa (2011).

Segunda a SNA (2016), na safra $15 / 16$ o total de grãos produzidos foi próximo a 187 milhões. A soja, principal grão produzido no Brasil teve produção de 95,4 milhões de toneladas. O milho teve um total de produção de cerca de 67 milhões de toneladas. O trigo, principal cultura de inverno, teve sua produção de cerca de 6,2 milhões de toneladas.

Segundo a Conab (2016), o estado de maior produção nacional na safra 2014/2015 foi o estado do Mato Grosso, seguido por Paraná e o Rio Grande do Sul. A tabelaı apresenta a produção nos estados brasileiros.

Em Minas Gerais a soja é o segundo grão de maior produção, ficando somente atrás do milho (Tabela 1). O milho contribui com $56 \%$ da safra de grãos no estado, já a soja tem participação de 33,6\%. Somados os dois produtos representam quase 90\% da produção mineira de grãos (SEAPA, 2017). As informações supracitadas podem ser vistas com detalhes na Tabela 1. 
Tabela 1 - Produção de soja por estado no Brasil

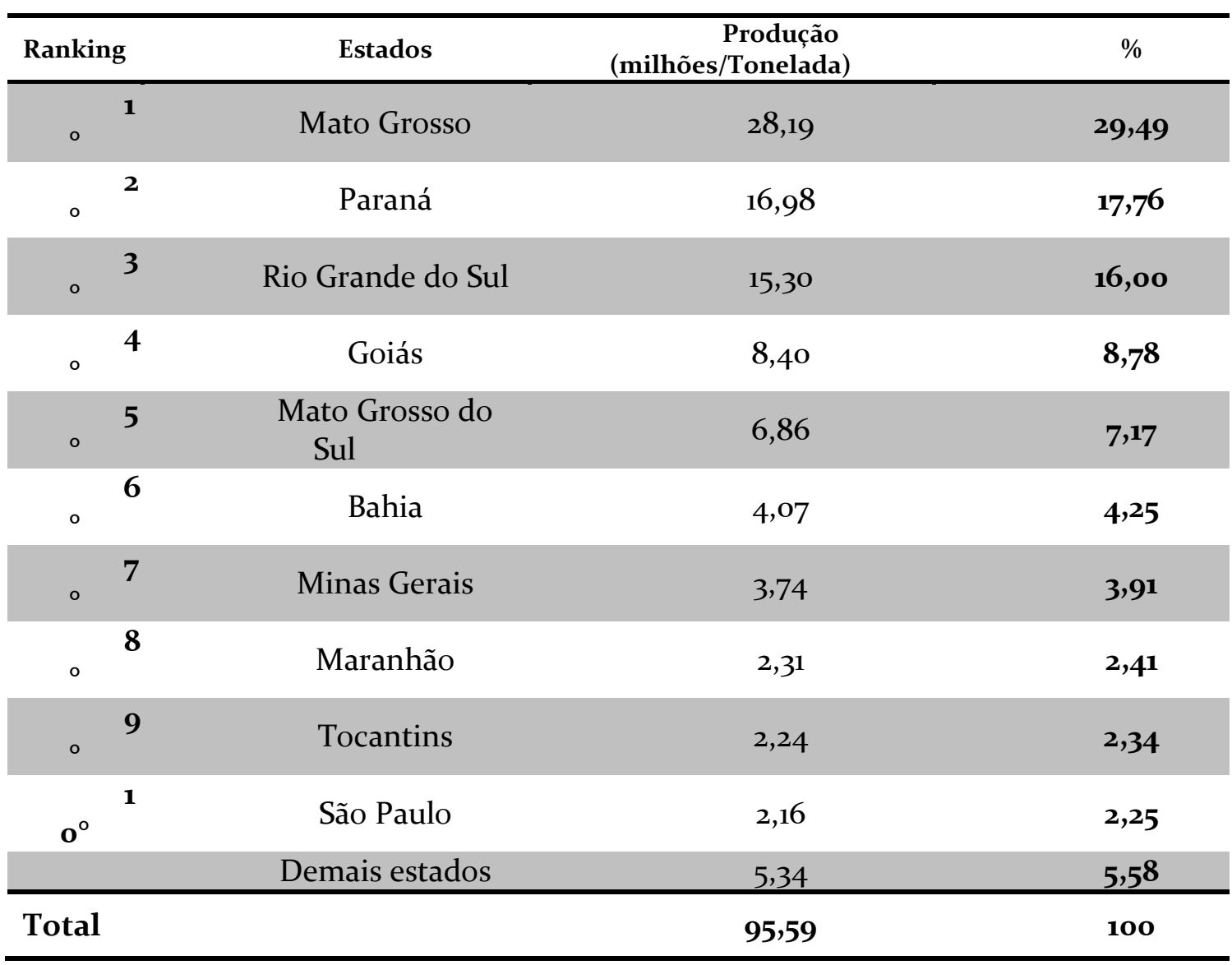

Fonte: Adaptado de Informativo Celeres (2015).

Segundo a Seapa (Secretaria de Estado de Agricultura, Pecuária e Abastecimento de Minas Gerais), a soja e milho têm uma importância estratégica para a pecuária mineira, com participação expressiva nas formulações das rações, e resultados positivos com a produção destes cereais asseguram fontes de proteínas (carnes, ovos, leite) (SEAPA, 2017).

As perdas na cadeia produtiva de soja ocorrem por diversos fatores. Segundo a Conab (2016) essas perdas referem-se principalmente a condições climáticas adversas. As perdas nos estados a seguir tiveram a seguinte representatividade: Rio Grande do Sul, 43,8\% (5,09 milhões de toneladas), Paraná com 30\% (4,63 milhões de toneladas) e Mato Grosso do Sul com 10,4\% (539,9 mil toneladas).

O transporte apresenta fatores que contribuem para as perdas, como: o tipo de caminhão utilizado, o carregamento e descarregamento inadequado, a distância percorrida, qualidade da via e transbordo entre modais. Segundo Semprebom (2009) e Rosa e Mikaya (2011), as perdas ocorrem por vazamento em unidades de transporte em más condições; falta de calibragem das unidades de pesagem; diferenças de umidade do produto; operação de carga e descarga, fraudes de transportadores; perdas nas rodovias, e manuseio inadequado na movimentação.

No Brasil o uso desse modal é de $62 \%$, o hidroviário representa $20 \%$, e o ferroviário $18 \%$, enquanto nos Estados Unidos da América o rodoviário representa $16 \%$, o hidroviário $5 \%$ e o ferroviário 23\% (CONAB, 2016).

Morais, Mayorga e Filho (2005) afirmam que de 5\% a 10\% de tudo que é cultivado acaba se perdendo na propriedade ou durante a armazenagem e transporte. Campos e Fachel (2010) afirmam que o Brasil é o país que consegue a maior produtividade de soja por hectare do mundo, quando 
comparado com os Estados Unidos, produz $11 \%$ a mais por hectare, porém perde sua competitividade nas perdas decorrentes da má qualidade das operações de transporte.

Outro fator de grande responsabilidade das perdas de grãos de soja são as condições de estado das rodovias de escoamento da soja. As estradas estão cheias de buracos, muitas vezes causados pela falta de manutenção, asfalto de má qualidade e excesso de peso dos caminhões, sendo nas propriedades rurais ou nas cidades (CAMPOS; FACHEL, 2010).

A seção a seguir apresenta os procedimentos metodológicos utilizados no estudo.

\section{Metodologia}

A pesquisa foi realizada na Cooperativa Alfa (a pedido da própria empresa esse foi o nome dado para não expor a organização), localizada em Unaí, Minas Gerais. A cooperativa Alfa há mais de 30 anos oferece os seguintes serviços: planejamento, armazenagem e comercialização da produção de seus associados. Essa cooperativa tem uma localização estratégica, pois fica na região de um dos maiores centros de produção de grãos do Brasil.

Com o objetivo de mapear as operações inerentes ao processo de armazenagem da soja da Cooperativa Alfa, e com vistas a identificar etapas onde há maior incidência de perdas do grão, este estudo foi baseado em um estudo de caso, com caráter exploratório.

Yin (2001) considera o estudo de caso uma descrição ou explicação abrangente dos muitos elementos de uma determinada situação social, por meio do qual o pesquisador busca conhecimentos geralmente aplicáveis além do caso específico analisado, mas ressalta que o estudo de caso por si só não garante tal generalização. Uma vantagem do método é possibilitar uma análise mais ampla, que considere todos os componentes que envolvem o caso escolhido e, também, por possuir um caráter intensivo, possibilita identificar relações que, de outra forma, não seriam descobertas.

Do ponto de visa da abordagem, este estudo se classifica como qualitativo. Essa modalidade de pesquisa não se preocupa com representatividade numérica, mas com o aprofundamento da compreensão de um grupo social, de uma organização. Os pesquisadores que utilizam os métodos qualitativos buscam explicar o porquê das coisas, exprimindo o que convém ser feito, mas não quantificam os valores e as trocas simbólicas, nem se submetem à prova de fatos, pois os dados analisados não são métricos (suscitados e de interação), e se valem de diferentes abordagens (GIL, 2002).

Para analisar o processo de armazenagem da soja dentro do armazém da Cooperativa Alfa foram feitas observações diretas quanto ao processo de armazenagem da soja, além de entrevistas semiestruturadas com os empregados e gestores realizadas pessoalmente, bem como uma posterior análise de fotos e vídeos realizados durante a pesquisa.

Para mapear as operações inerentes ao processo de armazenagem da soja foram utilizados os dados coletados nas observações diretas não participantes e nas entrevistas. Como suporte técnico foi utilizado o Software Bizaggi, que ajudou a mapear todo processo e que será apresentado adiante.

Para identificar as etapas onde há ocorrência de perdas significativas do grão foram feitas observações diretas não participantes, onde o foco foi o processo de armazenagem da soja. Também foram realizadas entrevistas semiestruturadas com colaborados do setor e com o Diretor Geral da Cooperativa. 
Para propor soluções que possam mitigar as perdas, foi utilizado um levantamento bibliográfico das técnicas de controle que podem ser utilizadas para reduzir as perdas constatadas no processo de armazenagem.

A figura 2 apresenta de forma elucidativa as etapas seguidas nesta pesquisa.

Figura 2- Relação entre objetivos específicos e procedimentos técnicos adotados

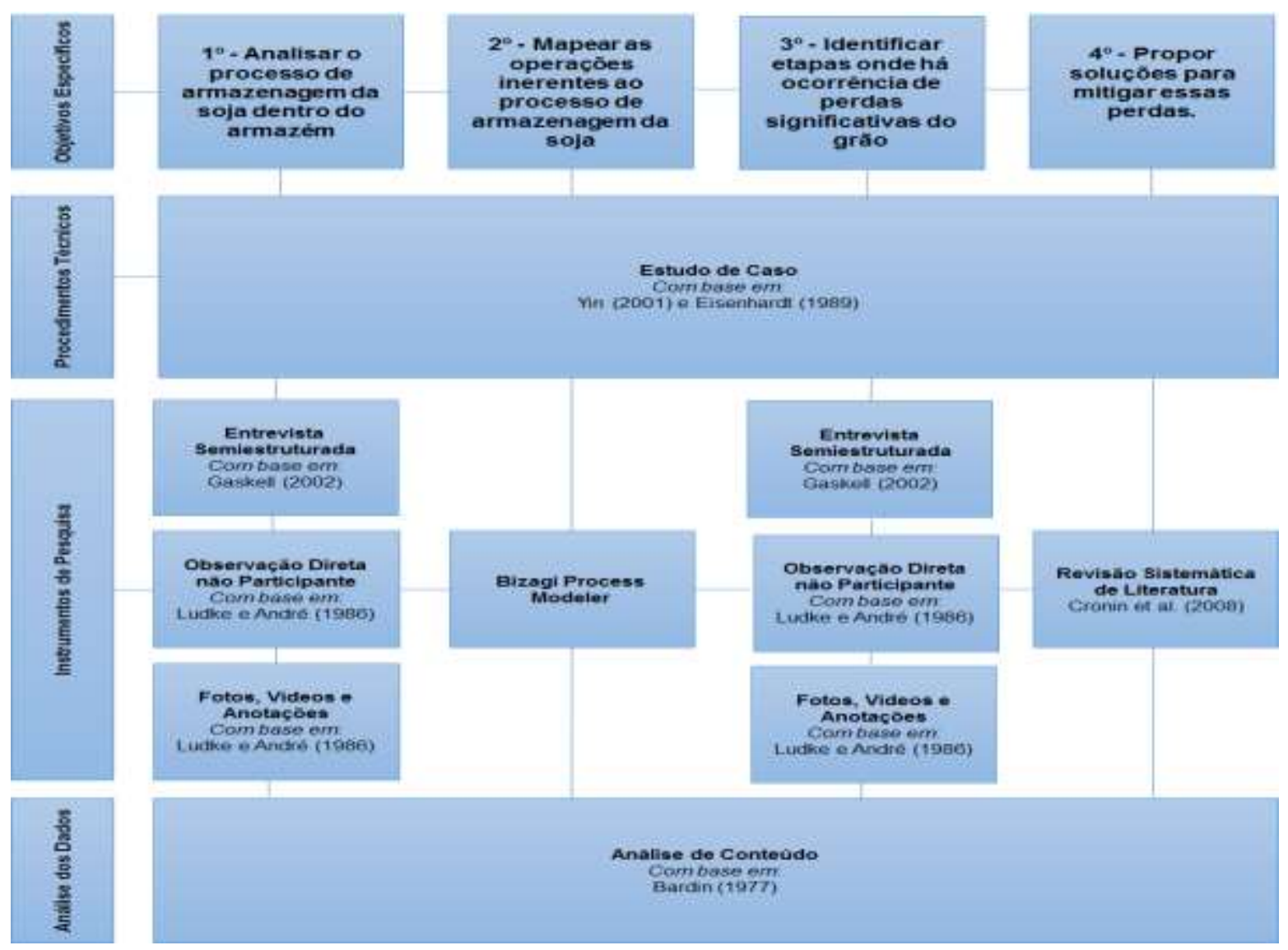

Fonte: elaboração própria.

Conforme apresentado na figura 2, o objetivo proposto alinha-se aos procedimentos técnicos, o que proporcionou maior credibilidade e robustez aos dados coletados, que serão apresentados e discutidos na próxima seção.

Para a análise e tratamento dos dados, optou-se por adotar a análise de conteúdo, conforme proposto por Bardin (1977). A lógica se deu pela importância de estabelecer categorias de análise para os dados coletados no caso analisado. Adotou-se a categorização a posteriori, conforme Bardin (1977).

\section{Resultados}

Nesta seção, os resultados são apresentados em concordância com o objetivo proposto no estudo. Paralelamente, são discutidos à luz do referencial teórico já apresentado. Primeiramente, apresenta-se o mapeamento e a análise do processo de armazenagem da soja, destacando-se as principais operações associadas. Ademais, baseado nesse mapeamento, são identificadas as etapas nas quais podem ocorrer perdas significativas do grão. Finalmente, busca-se elencar possíveis medidas que visem mitigar essas perdas. 


\subsection{Mapeamento e análise do processo de armazenagem da soja}

Essa seção apresenta o mapeamento do processo de armazenagem da soja dentro das instalações da Cooperativa Alfa. A figura 3 apresenta esse processo em forma de fluxograma.

Percebeu-se que as operações que compõem essa atividade são relativamente simples, mas exercem influência direta nas demais atividades desenvolvidas pela cooperativa, como a comercialização, por exemplo. Entende-se que as ações de redução de perdas na armazenagem de grãos iniciam-se, fundamentalmente, pelo conhecimento pormenorizado das operações que compõem tal processo.

Figura 3 - Processos de armazenamento dos grãos

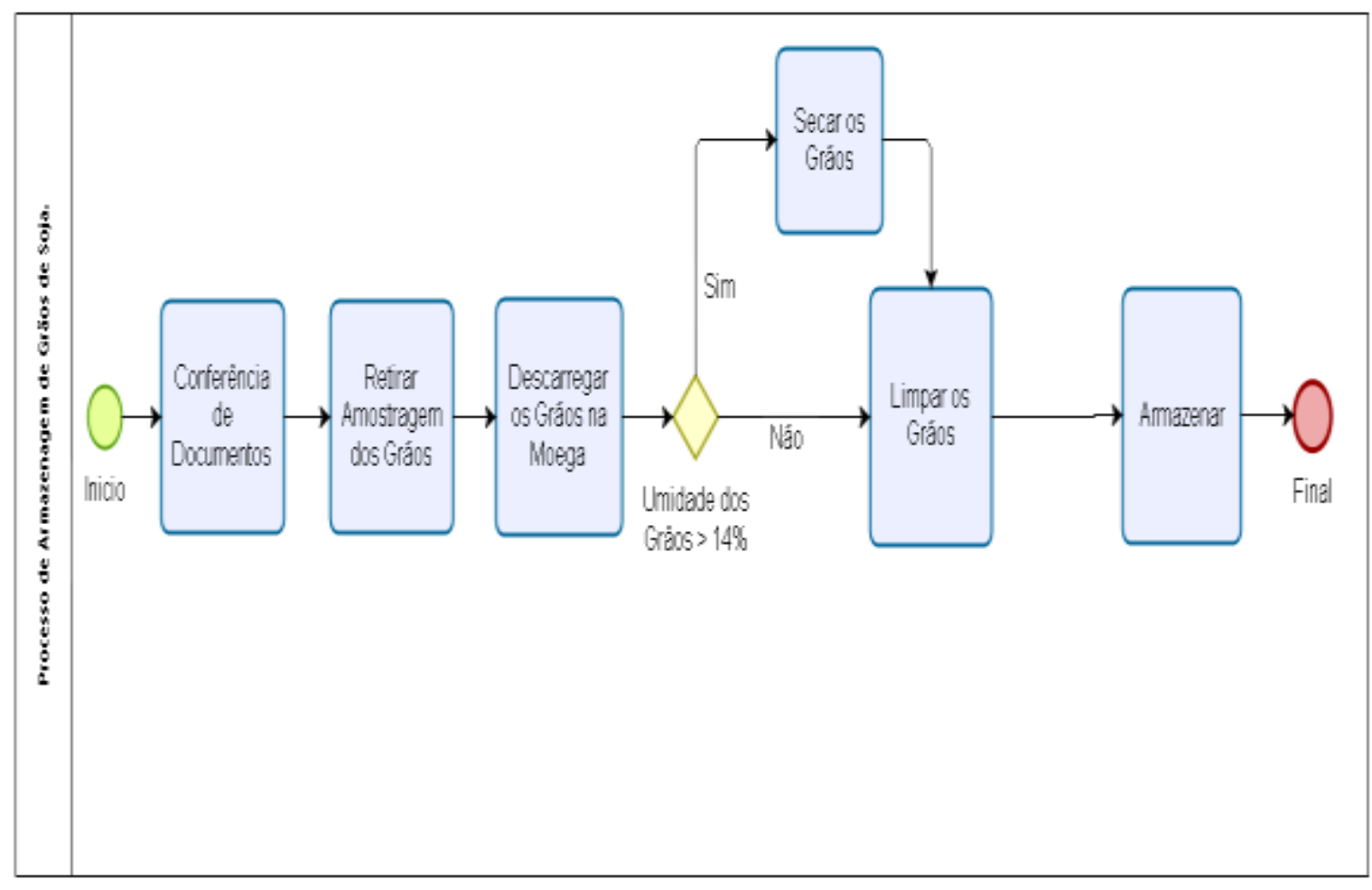

Fonte: elaboração própria.

No processo de armazenagem notou-se a existência de seis etapas, conforme apresentado na figura 3, são elas: (1) conferência dos documentos dos produtores e da carga; (2) retirar amostras dos grãos; (3) descarga dos grãos na moega; (4) secagem; (5) limpeza dos grãos e; (6) o armazenamento propriamente dito.

A etapa de conferência dos documentos é realizada por um colaborador cujo posto de trabalho encontra-se instalado na entrada da cooperativa, denominada balança. Esse setor é responsável por permitir ou não a entrada do caminhão para dentro do pátio, tendo diversos parâmetros como base para a tomada dessa decisão. Nesse setor é feita a conferência dos documentos dos produtores rurais e da carga, a confecção de recibos dos grãos por parte da cooperativa e a pesagem do caminhão junto com a carga na entrada. Também é realizada a retirada de amostras dos grãos para realização dos testes de umidade e transgênese. $O$ teste de transgênese somente é realizado caso o produtor declare em nota que a soja entregue não seja transgênica. Ao sair, realiza-se novamente a pesagem do caminhão.

A retirada da amostra é feita de forma totalmente automatizada. Um equipamento eletrônico retira a amostra da carga do caminhão e leva a mesma para o laboratório, onde é feito o teste de teor 
de umidade e de soja transgênese, caso não declarado em notas. Essas amostras são estocadas por um determinando período de tempo (contraprovas). Isso ocorre porque o produtor pode requerer uma amostra do seu produto a qualquer momento, e também por questões relacionadas à rastreabilidade dos grãos. Esse laboratório é situado no mesmo local da conferência dos documentos.

A descarga de grãos nas moegas é o primeiro passo para o armazenamento, já dentro da planta de armazenagem. É um local onde são despejados os grãos, sendo que essa estrutura está localizada no solo para facilitar o escoamento. Os caminhões ficam parados em cima da estrutura da moega e despejam os grãos. Essa operação ocorre de duas formas, uma totalmente automatizada, feita pelo próprio caminhão, onde os grãos escorrem pelas aberturas da carroceria posicionada na lateral e na parte de traz. Os caminhões mais antigos possuem aberturas denominadas "bicos", os quais se localizam na parte inferior de sua carroceria. Com isso, necessita-se da ajuda de colaboradores para fazer a movimentação dos grãos até os bicos que, após serem abertos, escorrem para dentro da moega.

A etapa de secagem tem a finalidade de retirar água contida nos grãos. É definida pela transferência de calor e massa (umidade) entre o produto e o ar quente, utilizado para fazer a secagem. O nível de umidade pré-estabelecido pela cooperativa é de, no máximo, $14 \%$, para que os grãos não necessitem passar pelo secador. Os grãos que se encontram acima desse nível devem passar pela secagem até atingir esse nível.

A secagem dos grãos na cooperativa Alfa é feita por dois grandes secadores alimentados por madeira. Os grãos são transportados para dentro dos secadores por esteiras e tubos, os quais ficam por um determinado tempo para que o processo de secagem se realize por completo. Após a secagem, retiram-se os grãos através de esteiras ou tubos. Em seguida, os grãos são levados para a etapa de armazenamento. A limpeza é realizada somente quando os grãos estão em conformidade com o nível de umidade estabelecido.

A limpeza é realizada de forma automatizada, com o uso de máquinas que retiram as impurezas. Essas máquinas possuem peneiras que fazem a separação dos grãos de soja dos rejeitos e impurezas. A Cooperativa Alfa possui duas máquinas que fazem esse procedimento, essencial para o armazenamento, pois com a limpeza consegue-se armazenar somente os grãos, otimizando o espaço. A cooperativa possui oito silos para o armazenamento da soja e de milho. Dois silos são antigos e horizontais. Seis possuem estrutura vertical e foram construídos com as mais modernas tecnologias de aeração (ventilação) que se encontra no mercado.

\subsection{Operações onde há ocorrência de perdas significativas do grão}

Verificou-se que em todas as etapas que integram o processo de armazenagem da soja há perdas, em maior ou menor grau. Dessas, constatou-se algumas operações nas quais há maior incidência, sendo elas: (1) perdas na movimentação dos grãos dentro da cooperativa; (2) perdas dos grãos nas moegas; (3) perdas na etapa de secagem; (4) perdas na etapa de armazenagem. A figura 4 apresenta essas etapas de forma mais elucidativa. 
Figura 4 - Operações com incidência de perdas

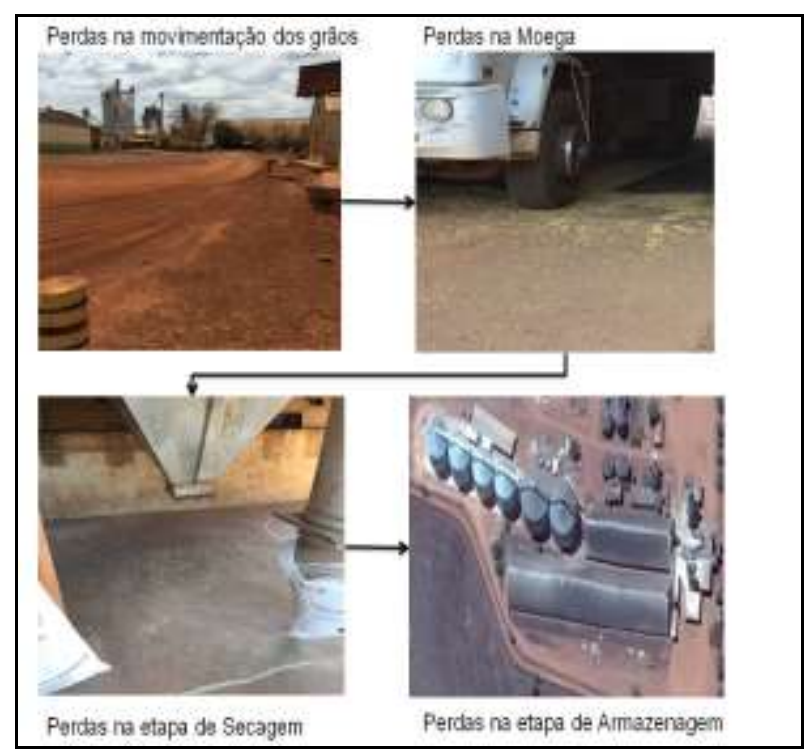

Fonte: elaboração própria.

As operações apresentadas na figura 4 mostram de forma clara aquelas que têm maior potencial de perdas.

Após o Check-In e a conferência do produto na recepção, o caminhão segue até a moega indicada. Este caminho dentro da própria cooperativa é longo e o trajeto não possui pavimentação asfáltica, além de possuir alto grau de desnível de suas estradas.

Verificou-se que muitos caminhões transportam os grãos com a capacidade acima do permitido pelo fabricante. De acordo com informações coletados com os colaboradores do setor de armazenagem essa é uma prática recorrente. Percebeu-se que essa prática está relacionada com a busca da redução de custos, haja vista que esse serviço tem custos elevados.

Notou-se também que a maioria dos caminhões são antigos, com suas carrocerias apresentando avarias. Percebeu-se que muitos grãos são perdidos no trajeto em função da falta de estrutura adequada dos caminhões e pelo alto grau de movimentação da carga em função dos desníveis.

Essa constatação corrobora com as ideias dos pesquisadores do Centro de Pesquisa Econômica Aplicada da Universidade de São Paulo - CEPEA/USP. Esses autores também identificaram que a perda da soja é bastante elevada, uma vez que os caminhões muitas vezes são carregados além do peso permitido pelo fabricante, o que aumenta a possibilidade de derramamento de grãos em seu trajeto (CEPEA/USP, 2013).

Ademais, constatou-se que a moega é o local onde há um dos maiores níveis de perdas. Existem duas formas para o descarregamento dos caminhões: manual, para os antigos; automática, para os veículos mais novos e modernos. Notou-se que na moega existe uma passagem (fluxo que a soja caminha) na qual não possui nenhum furo ou vazamento para que os grãos possam passar com facilidade.

Para o descarregamento dos caminhões antigos é necessário o auxílio de colaboradores, aumentando os custos. Foi possível verificar que no momento em que começam a despejar os grãos, esses ficam retidos na passagem que existe para os caminhões por não possuir nenhum tipo de furo ou vazamento. Deste modo, muitos grãos são jogados para fora da moega pelo alto nível de acúmulo 
nos trilhos de passagem dos caminhões. Dessa forma os grãos não conseguem escorrer com fluidez para dentro da estrutura da moega.

Nos caminhões que utilizam um sistema de pistões que fazem o levantamento da carroceria, tanto para o alto como para o lado, os grãos caem sobre as plataformas de acesso, mas em menor quantidade.

Nas operações de recepção e expedição a queda de grãos pelas instalações pode ser considerada comum. Entretanto, foi constatado que há baixo reaproveitamento desses produtos na limpeza do pátio, e que acontece com baixa frequência (PEIXOTO; BATALHA; MENDONÇA, 2016).

Posteriormente, observa-se que o processo de secagem tem como objetivo a diminuição dos níveis de teor de umidade dos grãos para um nível adequado de armazenamento, onde acontecem perdas qualitativas ou quantitativas. Os grãos são formados de massa e líquido (água), e caso ocorra uma secagem acima do necessário, o grão perde líquido, com isso, perde qualidade, o que o torna mais duro, tornando, inclusive, sua comercialização mais difícil.

Percebeu-se que os secadores que realizam esta etapa, por estarem muito antigos, possuem sistemas de controle de temperatura desatualizados, facilitando a ocorrência de erro do operador. Consequentemente, os grãos podem secar mais que o recomendado, ou ficarem com o nível de umidade acima do recomendado. Com os grãos mais secos, a sua comercialização fica quase inviável. Se os grãos ficarem úmidos e forem para o armazenamento, podem ocorrer ataques de fungos e bactérias, contaminando todo o silo.

Na armazenagem dos grãos dentro dos silos foi constatado que pode ocorrer diversas perdas, como: os grãos podem azedar ou mofar, ou haver ataques de roedores. Fungos, também denominados mofos, são microrganismos multicelulares e filamentosos, que ao infestarem os grãos e alimentos podem produzir substâncias tóxicos tais como mico toxinas (FONSECA, 1999). Ainda segundo o autor, os fungos do armazenamento demandam menor quantidade de água, desta forma, proliferam em maior intensidade na massa de grãos no período de armazenagem.

O fato de os grãos serem armazenados dentro dos silos com diferenças no nível de teor de umidade e de temperatura da massa, são os principais motivos para a proliferação dos fungos, e para o azedamento dos grãos.

O problema dos silos antigos, chamados de "graneleiro", é manter o nível de umidade padrão em todos os grãos, por se tratar de uma estrutura horizontal. A manutenção da umidade dos grãos que ficam na parte inferior é mais complexa e propensa à infestação dos fungos. A parte dos grãos que fica na parte superior é a que mais recebe o tratamento de umidade. Caso ocorra muito tratamento, a ocorrência dos fungos também se eleva. Isso vai ao encontro dos preceitos de D’arce (2012), dizendo que a armazenagem pode causar perdas na cadeia caso as unidades armazenadoras não observem as técnicas adequadas para cada tipo de grão.

Contatou-se também que as impurezas, caso não forem devidamente retiradas na limpeza dos grãos são impulsionadores para o desenvolvimento de fungos. Indica-se, contudo, que o controle de pragas seja bastante eficaz, visto que a presença de roedores e insetos está associada ao desenvolvimento e proliferação de fungos. Visando a qualidade dos grãos, no momento em que o silo estiver totalmente vazio foi sugerido realizar a limpeza interna do mesmo, pois o pó e restos de matérias podem ajudar no desenvolvimento dos fungos. Locais onde se encontram grande quantidade de grãos são ideais para a proliferação de roedores e insetos para fazer a utilização desses grãos em sua alimentação.

Essas impurezas podem retardar o processo de secagem, acelerar o surgimento e desenvolvimento de microrganismos, e facilitar a proliferação de insetos. A escolha das peneiras que 
127| Mapeamento das perdas da armazenagem da soja: um estudo...

serão utilizadas para a retirada das impurezas deve ser feita de forma criteriosa (BRAGANTINI; VIEIRA, 2004).

Toda ação de movimentação dos grãos na troca de etapas no processo de armazenamento na Cooperativa Alfa é realizada por esteiras e tubos. Por exemplo, a retirada de amostras é feita por tubos. Já nas outras etapas a movimentação dos grãos é realizada por esteiras. Segundo os colaboradores, os pontos críticos do processo é uma ação corretiva rápida para mitigar as perdas. A movimentação dos grãos dentro do pátio da cooperativa, realizadas pelos caminhões, que na maioria das vezes está com a sua capacidade de utilização acima do permitido, tornam esses pontos críticos, e geram a maioria das perdas.

\subsection{Propostas para mitigar perdas}

A seguir é apresentado as soluções propostas para minimizar as perdas da soja dentro do armazém da cooperativa Alfa. Convém ressaltar que tais propostas foram baseadas em trabalhos empíricos já realizados, levantados na literatura especializada.

1: Perdas na movimentação dos grãos: Para reduzir o problema de grãos jogados ao chão dentro da cooperativa Alfa, a pavimentação das vias, com o nivelamento das mesmas faria com que a carga não sofresse com a movimentação que os caminhões fazem, reduzindo as chances do grão ser lançado para fora da carroceria. A pavimentação também diminuiria a quantidade de pó causado pelas vias de terra, e com isso a cooperativa conseguiria manter a limpeza de seus escritórios e ajudaria a manter a saúde de seus colaboradores. Para os caminhões que transportam a quantidade de grãos acima do permitido, a cooperativa poderia estabelecer regras de verificação de pesagem, mediante balanças para fazer a aferição. Os produtores ou transportadores deveriam utilizar somente carrocerias apropriadas para a realização do transporte, ou se estivesse em boas condições para o transporte. (RODRIGUES, 2008; MUNOZ; PALMEIRA, 2006).

2: Transbordo dos grãos nas moegas: Para mitigar o acúmulo de grãos na moega, recomenda-se que a cooperativa adote uma nova plataforma para a passagem dos caminhões que possua furos ou vazamentos para que os grãos pudessem cair/escorrer dentro da moega com mais facilidade. Dessa forma, evitaria o acúmulo dos grãos na passagem e, consequentemente, reduziria a perda dos grãos. A nova passagem deveria ser feita de material resistente e de forma vazada, como o ferro. Como dito anteriormente, a atual plataforma de passagem é de madeira e não possui nenhum furo/vazamento. Desta forma, os grãos não conseguem cair com maior fluidez dentro da moega (RAMOS FILHO; ATAMANCZUK; MARÇAL, 2010).

3: Perdas na etapa de secagem: Sobre os sistemas desatualizados de controle de temperatura do secador, recomenda-se que a cooperativa faça uma atualização, pois com o controle maior sobre a temperatura conseguir-se-ia manter um nível adequado de líquido e massa dos grãos. Sobre as perdas dos grãos causados pelos movimentos das esteiras, a criação de um plano de manutenção preventiva sobre elas seria o suficiente para resolver o problema, pois atualmente na cooperativa não há um plano para a realização das manutenções preventivas em suas máquinas (KIELISCH et al., 2017). As manutenções, em caráter corretivo, como estão sendo realizado atualmente, são feitas a partir do momento em que os equipamentos não estão no funcionamento normal, ou prestes a quebrar.

4: Perdas na armazenagem: Deve ser feito o controle de umidade do ar para diminuir o problema dos fungos. Por isso, a cooperativa deve sempre manter o controle, com monitoramento constante, para que haja um equilíbrio entre todos os grãos dentro do silo. Dessa forma, diminuirão as chances de perdas dos grãos (PUZZI, 1999; LORINI, 2001; LAZZARI; KARKLE; LAZZARI, 2006; SANTOS, 2006; PIMENTEL; FONSECA, 2011; SILVA; AFONSO; DONZENELLES, 2000). A cooperativa possui quatro novos silos que são equipados com novos e modernos sistemas de aeração em todas as partes do silo, assim o controle de umidade não é muito complexo. Os dois silos antigos 
também possuem um sistema que faz esse controle de umidade, mas somente nos grãos que ficam na parte superior, por isso, sempre deve manter um movimento dos grãos para que todos fiquem em conformidade. Com relação ao problema com os roedores e isentos, a cooperativa possui um contrato com uma empresa terceirizada, a qual realiza o processo de controle e prevenção dos mesmos, e talvez seria interessante integrar verticalmente esse processo para garantir maior qualidade.

\section{Conclusões}

O presente trabalho buscou realizar o mapeamento das operações inerentes ao processo de armazenagem da soja em um armazém localizado em Unaí, MG, com o intuito de identificar etapas onde há maior incidência de perdas do grão.

Foi realizada uma análise de todo o processo de armazenagem, e notou-se que existem, na sua totalidade, seis operações relacionadas ao processo de armazenamento da Cooperativa Alfa.

Verificou-se que essas operações são realizadas de forma amadora, devido a constatação da falta de documentação dos processos e dos desperdícios identificados. Dependo do nível de umidade que o produto se encontra, cada etapa é crucial, necessitando o máximo de profissionalismo para garantir a qualidade e a redução de perdas, não podendo ser negligenciada nenhuma etapa, pois, somente com todas concluídas, é possível alcançar os padrões de qualidade mínima exigida.

Constatou-se que no processo de armazenagem existem diversos pontos onde há incidências de perdas dos grãos, acontecendo de forma recorrente. Isso gera impacto econômico negativo para a cooperativa, como também para o cooperado, que utiliza o espaço da cooperativa para armazenar seus grãos. Ao todo foram quatro pontos onde a incidência de perdas é notável: (1) a movimentação dos caminhões dentro da cooperativa, que são carregados de forma inadequada, acima do peso; (2) perdas na moega; (3) perdas na secagem dos grãos; e (4) perdas na armazenagem.

Todas as sugestões de melhorias para a mitigação das falhas no processo de armazenamento na Cooperativa Alfa tiveram fundamentação teórica, encontradas soluções alternativas em trabalhos científicos, livros e em revistas técnicas. Portanto, foi possível apontar seis etapas indispensáveis para a melhoria da armazenagem do produto. Cada uma possui grau de importância dentro do processo e tem suas capilaridades. Todas as etapas são passíveis de perdas, porém, notou-se que existe quatro pontos nas quais podem ser potencializadas, como as citadas nas propostas de melhorias.

Existem diversos fatores que causam as perdas, podendo ser de natureza biológica, como a proliferação de pragas; falta de infraestrutura nas instalações, máquinas e equipamentos que realizam tal operação que não estão em perfeito estado de conservação; ou até mesmo pela falta de manutenção preventiva.

As contribuições deste estudo apresentam-se em duas perspectivas. Para a academia o trabalho avançou nas análises relacionadas ao setor de armazenagem de soja, pois se entende que esse campo do conhecimento ainda carece de aprofundamento de estudos. No contexto da prática gerencial da cooperativa, este trabalho contribui no sentido da colaboração para o entendimento melhor do processo como um todo, como também uma melhor noção sobre a real situação das condições das instalações físicas.

Destaca-se que alguns fatores limitaram o desenvolvimento do estudo. O principal deles diz respeito à dificuldade de coleta de dados junto à cooperativa, sobretudo pela falta de documentos sobre o processo. Dito isso, indica-se que novos estudos busquem também investigar e encontrar formas para a solução desses problemas, assim como uma quantificar as perdas, que atrapalham de forma drástica a competitividade das cadeias produtivas no Brasil. 


\section{Referências}

ARAÚJO, J. M. Fundamentos de Agronegócios. 2. ed. São Paulo: Atlas, 2005.

ALVAREnGA, A. C., NOVAeS, A. G. N. Logística Aplicada - Suprimento e Distribuição Física. za edição. São Paulo: Edgar Blücher, 2000.

AYERS, J.B. (Ed.). Handbook of supply chain management. 2. ed. Boca Raton-US: Auerbach, 2006. P. 608

BAILEY, J. E. Whole grain storage. In: Christensen, C. M. (ed.) Storage of cereal grains and their products. St. Paul: AACC, p. 333-36o, 1974.

BALLOU, R. H. Logística empresarial: transportes, administração de materiais e distribuição física. São Paulo: Atlas, 1993.

BARDIN, L. Análise de conteúdo. Lisboa: Edições 70, 1977.

BAUDET, L.; VILLELA, F. A. Armazenamento Garantindo o Futuro. Pelotas: Editora Becker e Peske Ltda, p.28-32, 2000.

BRAGANTINI, C.; VIEIRA, E. H. N. Secagem, armazenamento e beneficiamento. Embrapa Arroz e Feijão, 2004.

BOWERSOX, D. J. \& CLOSS, D. J. Logística empresarial: o processo de integração da cadeia de suprimento. São Paulo: Atlas, 2006.

CAMPOS, J., FACHEL, F. Vantagem da produção de soja brasileira é perdida na logística de transporte. Mato Grosso: Jornal do Globo, 2010.

CAMPOS, T. B. A importância do instituto biológico no desenvolvimento dos estudos sobre pragas de grãos e produtos armazenados. Instituto Biológico, Centro de Pesquisa e Desenvolvimento de Sanidade Vegetal. São Paulo, p.85-86, 2008.

INFORMATIVO CELERES, Produção de Soja Nos Estados Brasileiros Na Safra 14/15. 2015. Disponível em: http://www.celeres.com.br/ic15-07-projecao-de-safra-soja-julho-2015/. Acesso em 30 de Mai. de 2018.

CENTRO DE ESTUDOS AVANÇADOS EM ECONOMIA APLICADA - CEPEA/ESALQ/USP. Série de preços - Soja. 2013. Disponível em: <http://www.cepea.esalq.usp.br/soja/>. Acesso em: 16 de set. 2018.

COMPANHIA NACIONAL DE ABASTECIMENTO (CONAB). BOLETIM INFORMATIOS SOBRE A SAFRA 15/16. 2016. www.conab.gov.br/OlalaCMS/uploads/arquivos/16_01_12_09_oo_46_bo letim_graos_janeiro_2016.pdf. Acesso em: 20 de abr. de 2018.

D’ARCE, Pós-colheita e armazenamento de grãos. Piracicaba: ESALQ, 2012. Disponível em: www.esalq.usp.br/departamentos/lan/pdf/Armazenamentodegraos.pdf. Acesso em: 18 de mai. De 2018 .

FERRARI, R. C. Utilização de modelo matemático de otimização para identificação de locais para instalação de unidades armazenadoras de soja no estado do Mato Grosso. Dissertação da Universidade de São Paulo: ESALQ, Piracicaba, 2006. 
FONSECA, M.P. Aphyllophorales lignocelulíticos da Reserva Biológica do Alto da Serra de Paranapiacaba, Santo André, SP. Tese de Doutorado, Universidade de São Paulo, São Paulo, 1999.

GABAN, A. C.; SILVA, F. M.; GUARNIERI, P.; BRISOLA, M. V. Evolução da produção de grãos e armazenagem: perspectivas do agronegócio brasileiro para 2024/25. Informe Gepec (Online), v. 21, p. 28-47, 2017.

GIL, A. C. Como elaborar projetos de pesquisa / Antônio Carlos Gil. - 4. ed. - São Paulo: Atlas, 2002.

GIOVINE, H.; MELO, L. C. Ciências Sociais Aplicadas em Revista - UNIOESTE/MCR - v.11 - n. 21 p. $99-2011$.

IPEADATA, Fonte de dados sobre preços da soja. 2017. Disponível em: www.ipeadata.gov.br. Acesso: 15 Mar. de 2018.

KIESLICH, L. R. KHATCHATOURIAN, O. BINELO, M. O.; DESSUY, M. S.; WINIK, S. V.; HAAS, C. F. F. Secagem artificial de grãos de soja: desenvolvimento de um controlador automático. Salão de conhecimento, v. 3, n, 3, 2017.

LEITÃO, F. O.; GRANEMANN, S, R.; SILVA, W. H. Custos da segregação na cadeia logística da soja para a oferta de um produto livre de transgênicos. Custos e Agronegocio On Line, v. 12, p. 220-244, 2016.

LEITÃO, F. O.; GRANEMANN, S. R.; FONSECA, A. P.; SILVA, W. H. Aspectos logísticos e institucionais que afetam a oferta da soja livre de transgênicos. RAMA - Revista em Agronegócio e Meio Ambiente, v. 11, p. 1283, 2018.

LAZZARI, S. M. N.; KARKLE, A. F.; LAZZARI, F. A. Resfriamento artificial para o controle de Coleoptera em arroz armazenado em silo metálico. Revista Brasileira de Entomologia, p.293296, 2006.

LIMA, J. A. F.; OLIVEIRA, I. P.; ROSA, S. R. A.; SILVA, A. J. S.; MORAIS, M. M. Controle De Pragas De Grãos Armazenados: Uso E Aplicação De Fosfetos. Revista Faculdade Montes Belos, v. 5, n. 4, p.180-184, 2012.

LORINI, I. Manual Técnico para o Manejo Integrado de Pragas de Grãos Armazenados. Embrapa - Trigo, p.12-68 2001.

MAIA, G. B. S.; PINTO, A. R.; MARQUES, C. Y. T.; LYRA, D. D.; ROITMAN, F. B. Panorama Da Armazenagem De Produtos Agrícolas No Brasil. Revista do BNDES, v. 40, p.161-194, 2013.

MORAIS, H. M. M., MAYORGA, M. I. O., FILHO, F. C. Análise do custo social das perdas no processo produtivo da banana no município de Mauriti-CE. 2005.

MORAES, M. F., BOIKO, T. J. P.; BIASI, C. Modelagem e simulação do processo de produção de farelo de soja politizado em uma cooperativa agroindustrial. In: ENCONTRO NACIONAL DE ENGENHARIA DE PRODUÇÃO, 29, 2009, Salvador. Anais. ENEGEP. Salvador: 2009.

MORABITO, R.; IANNONI, A. P. Logística Agroindustrial. In: BATALHA, M. O. Gestão Agroindustrial: GEPAI: Grupo de Estudos e Pesquisas Agroindustriais. São Paulo: Atlas, 2007. 
MUNOZ, C. C.; PALMEIRA, E. M. Desafios de Logística nas Exportações Brasileiras do Complexo Agronegocial da Soja. Revista Acadêmica de Economia, n.71, 2006.

NOVAES, A. Logística e Gerenciamento da Cadeia de Distribuição. 4ํㅗㄹ. Elsevier Brasil, 2004.

PEIXOTO; J. C.; BATALHA; M. O.; MENDONÇA, M. H. 2016, João Pessoa. Contextualização do sistema de transporte de grãos: um estudo multicascos em terminais intermodais da região sudeste brasileira João Pessoa: Enegep, 2016. 13 p.

PIMENTEL, M. A. G.; FONSECA, M. J. O. Secagem e Armazenamento. Embrapa Milho e Sorgo, 2011.

PINAZZA, L. A. Cadeia Produtiva da Soja. Série Agronegócios, Ministério da Agricultura, Pecuária e Abastecimento-Mapa v.2. 2006.

PUZZI, D. Abastecimento e armazenagem de grãos. Campinas: Instituto Campineiro de Ensino Agrícola. 1999.

RAMOS FILHO, J. A.; ATAMANCZUK, M. J.; MARÇAL, R. F. M. Seleção de técnicas de manutenção para processo de armazenagem através do Método de Análise Hierárquica. Revista Produção Online, v. 10, n. 1, 2010.

ROBERTI, D. F.; NETO, F. J. K.; CORREA, R. G. F. Descrição e análise da cadeia produtiva da soja no Rio Grande do Sul: uma aposta com foco no produtor rural. Trabalho de Conclusão de Curso, UFRGS, 2011.

RODRIGUES, P. R. A. Introdução aos sistemas de transporte no Brasil e a Logística Internacional. $4^{\circ}$ Ed. São Paulo: Aduaneiras, 2008.

ROSA, I. F.; MAKIYA, I. K. Sustentabilidade da soja brasileira no mercado internacional: gestão de trade off. 2011.

SANTOS, J. P. Controle de Pragas Durante o Armazenamento de Milho. Circular Técnica 84. Sete Lagoas, p.1-20, 2006.

SECRETARIA DE ESTADO DE AGRICULTURA, PECUÁRIA E ABASTECIMENTO DE MINAS GERAIS - SEAPA. Produção de soja no estado. 2017. http://www.agricultura.mg.gov.br. Acesso em: abr. 2018.

SEMPREBOM, P. A. Perdas no transporte agrícola. 2009. 57f. Monografia (Especialização), Especialização em Ciência Política e Desenvolvimento Estratégico, Faculdade Arthur Thomas, Londrina, 2009.

SILVA, J. S. S.; AFONSO, A. D. L.; DONZELLES, S. M. L. Secagem e Secadores. Viçosa, Cap 5, p.107137, 2000.

SLACK, N.; CHAMBERS, S.; JOHNSTON, R. Administração da produção. 3. ed. São Paulo: Atlas, 2009.

SOCIEDADE NACIONAL DA AGRICULTURA (SNA). Capacidade de Armazenagem no Brasil. 2016. sna.agr.br/capacidade-de-armazenagem-de-graos-continua-insuficiente-no-brasil/. Acesso em: 16 de abr. de 2018.

YIN, R. K. Estudo de Caso Planejamento e Método. 2. Ed. São Paulo: Bookman, 2001. 